\title{
Prenatal presentation of Walker-Warburg syndrome with a POMT2 mutation: an extended fetal phenotype
}

\author{
Sara H. El-Dessouky ${ }^{1 *}$ D, Heba Hosny ${ }^{2}$, Ahmed Ezz Elarab ${ }^{3}$ and Mahmoud Y. Issa ${ }^{4}$
}

\begin{abstract}
Background: Walker-Warburg syndrome (WWS) is a rare, lethal, genetically, and clinically heterogeneous congenital muscular dystrophy resulting from defective glycosylation of $a$-dystroglycan ( $a-D G$ ) and is associated with both cranial and ocular malformations. Prenatal detection of posterior fossa anomalies in association with hydrocephalus are nonspecific, however, an additional finding of eye anomalies are typical for WWS. The purpose of this report is to elucidate the pattern of associated malformations in a fetus with WWS born to 3rd degree consanguineously married couple. Additionally, the fetal ultrasonography revealed congenital heart disease, clenched hands, and talipes equinovarus; these findings have not been previously reported and represent an expansion of prenatal spectrum associated with WWS.
\end{abstract}

Case presentation: We report on a specific sonographic pattern of congenital anomalies including hydrocephalus, agenesis of corpus callosum, and Dandy-Walker malformation. Ocular abnormalities include microphthalmia, cataract, and an echoic structure suggestive of persistent primary vitreous. Other features include congenital heart disease, unilateral multicystic kidney, and previously unreported findings of bilateral clenched hands and talipes equinovarus. The molecular analysis detected a homozygous splicing mutation, c.924-2A>C, in the POMT2 gene; this variant segregated with the phenotype.

Conclusion: WWS syndrome has characteristic prenatal ultrasound findings which can improve the prenatal identification of this condition and help in guiding the molecular diagnosis and counseling. The detection of bilateral clenched hands and talipes equinovarus is a novel finding that further expands the phenotypic spectrum of WWS.

Keywords: Walker-Warburg syndrome, Ocular abnormalities, Clenched hands and talipes, Cystic kidneys, POMT2 gene

\footnotetext{
* Correspondence: saraeldessouky@yahoo.com

${ }^{1}$ Prenatal Diagnosis \& Fetal Medicine Department, Human Genetics and Genome Research Division, National Research Centre, Tahrir street, Dokki,

Cairo, Egypt

Full list of author information is available at the end of the article
}

\section{Springer Open}

(c) The Author(s). 2020 Open Access This article is licensed under a Creative Commons Attribution 4.0 International License, which permits use, sharing, adaptation, distribution and reproduction in any medium or format, as long as you give appropriate credit to the original author(s) and the source, provide a link to the Creative Commons licence, and indicate if changes were made. The images or other third party material in this article are included in the article's Creative Commons licence, unless indicated otherwise in a credit line to the material. If material is not included in the article's Creative Commons licence and your intended use is not permitted by statutory regulation or exceeds the permitted use, you will need to obtain permission directly from the copyright holder. To view a copy of this licence, visit http://creativecommons.org/licenses/by/4.0/. 


\section{Background}

Walker-Warburg syndrome (WWS; OMIM 236 670) is considered to lie at the most severe end of the spectrum of the congenital muscular dystrophies group, with a life expectancy of less than 3 years [1, 2]. It has a worldwide distribution, the overall incidence is unknown, however, and an estimated incidence rate of 1.2 per 100,000 live births has been previously reported in northeastern Italy $[3,4]$. A combination of congenital muscular dystrophy in association with ocular, cerebellar, and cerebral anomalies in addition to myopathy is considered to be pathognomonic of a spectrum of clinically and genetically heterogeneous disorders including Walker-Warburg syndrome (WWS), Fukuyama muscular dystrophy, and muscle-eye-brain disease $[3,5]$. All these autosomal recessive disorders, grouped under the term " $\alpha$-dystroglycanopathies," result from defective glycosylation of an $\alpha$ dystroglycan $(\alpha-D G)$ that is important for the structural integrity of the muscular and neural tissue and neuronal migration [6-8].

A clinical delineation of WWS has been described by Dobyns et al. [2]; aside the severe congenital muscular dystrophy with postnatal marked hypotonia and elevated levels of creatinine kinase (CK), the brain malformation is constantly present and represented by cobblestone lissencephaly, obstructive hydrocephalus, corpus callosum agenesis, and pontocerebellar hypoplasia with fourth ventricle dilatation, moreover, kinking of the brainstem and, less commonly, Dandy-Walker malformation and occipital cephalocele $[5,9,10]$. The ocular abnormalities affect the anterior and posterior chambers with resultant retinal detachment and blindness; additionally, optic nerve hypoplasia, iris malformation, cataract, microphthalmia, and megalocornea may be found [11-13]. Less frequent clinical manifestations include facial dysmorphic features with micrognathia, and cleft lip or palate $[14,15]$. The renal affection in WWS has not been described comprehensively in the literature. Recently, pathology reports identified multicystic dysplastic kidneys, renal cysts, unilateral kidney agenesis, or cystic kidneys as possible associations [16-19]. From several studies including large numbers of affected cases, it is estimated that POMT1, POMT2, POMGNT1, FKTN, LARGE, and FKRP account for approximately $42 \%$ of WWS cases. Additionally, there is no evident genotype-phenotype correlation, as most cases; the defective gene cannot be predicted from the clinical phenotype [1, 20-22].

Until recently, the prenatal diagnosis of WWS was described only during late pregnancy [23]. The technical evolution in ultrasound and molecular genetic diagnosis allowed possible early detection of this syndrome with the subsequent elucidation of its natural history [24]. Our report highlights the prenatal ultrasound findings of a fetus with WWS linked to homozygous POMT2 gene mutations.

\section{Case presentation}

A 26-year-old G3P1A1L0 female patient was referred in her 3rd pregnancy for a prenatal genetic consultation at 20 weeks' gestation following the detection of polyhydramnios and suspected abnormal posterior fossa in a female fetus. Paternal age was 36 years, and the parents were 1st degree paternal cousins of Egyptian descent. The couple is completely healthy, their medical and family histories were unremarkable, and their chromosomal analysis was normal. The pregnancy history was unremarkable, and the patient denied any maternal illnesses or exposure to teratogens.

Obstetric history included a previous male neonatal death at the age of 10 months with hydrocephalus, eye abnormalities, hypotonia, and persistent elevated CK. This was followed by an induced termination of a female fetus at 26 weeks' gestation due to ultrasound findings of hydrocephalus and a suspected Dandy-Walker malformation, and cephalocele amniocentesis was performed, and chromosomal analysis revealed normal female karyotyping but no further genetic tests or autopsies were performed.

During the current pregnancy, the patient was examined by Voluson E8 (GE Medical Systems, Zipf, Austria) ultrasound machines with $4-8 \mathrm{MHz}$ curvilinear abdominal probes and $5-9 \mathrm{MHz}$ curvilinear vaginal probe. Apart from markedly increased fetal head circumference 190 $\mathrm{mm}$ at the 95th centile for the corresponding gestational age, fetal biometric parameters were within limits. Moreover, throughout the examination there was a reduced fetal movement with clenched hands and bilateral talipes equinovarus. Fetal neurosonogram confirmed the presence of abnormal posterior fossa consisted of cerebellar vermis aplasia with communication between the fourth ventricle and a CSF-containing space in the midline, suggestive of Dandy-Walker malformation. There was also cerebellar hypoplasia with the transcerebellar diameter measuring $15 \mathrm{~mm}$ just below the 5 th centile for the corresponding gestational age. In addition to agenesis of corpus callosum, both lateral ventricles were grossly dilated and the third ventricle was also dilated in consistence with aqueduct stenosis or communicating hydrocephalus.

Assessment of the fetal face revealed macrocephaly, low-set ears, and micrognathia. The fetal eyes' examination revealed microphthalmia, hyperechoic, and opaque lenses suggestive of cataracts and unilateral abnormal echogenic mass with irregular borders expanding from the posterior lens surface to the posterior wall of the right eye suggestive of persistent primary vitreous. The detailed evaluation of fetal cardiac structure by fetal echocardiography demonstrated atrioventricular septal defect; additionally, the fetus had enlarged multicystic dysplastic left kidney measuring $45 \mathrm{~mm}$ (range; 16-30); the right kidney had a normal shape and size (Fig. 1). 

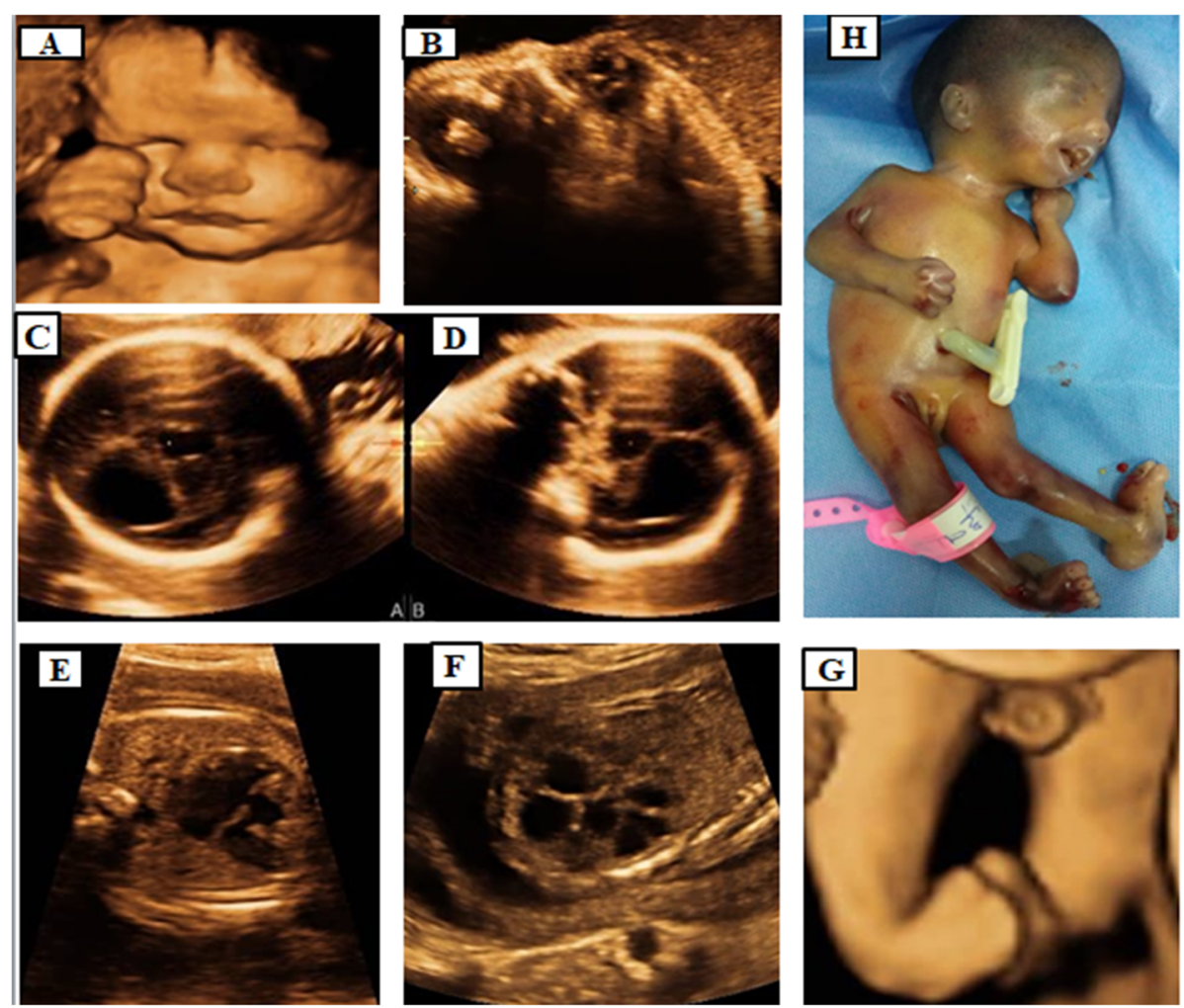

Fig. 1 Fetus at 20 weeks' gestational age with ultrasound findings of Walker Warburg syndrome. a Three-dimensional surface rendering of the fetal face showing bilateral microphthalmia and a clenched hand. b Axial US through the orbits showing asymmetric affection with the left eye demonstrating homogeneous opacity of the lens in the left eye consistent with cataract, and the right eye showing echogenic band consistent with hyperplasia of the vitreous chamber. c Axial trans-ventricular plane of the fetal head demonstrating agenesis of corpus callosum, dilatation of the third ventricle, and the anterior and posterior horns of the lateral ventricles. $\mathbf{d}$ Axial transcerebellar plane of the fetal head showing cerebellar hypoplasia and vermian agenesis with open fourth ventricle communicating with the cisterna magna and non-expanded posterior fossa. e Fetal echocardiogram demonstrating AVSD (atrial ventricular septal defect). $\mathbf{f}$ Coronal US image of multicystic dysplastic kidney (MCDK) showing enlarged kidney with several subcortical small cysts. $\mathbf{g}$ Three-dimensional surface rendering mode of lower extremities showing hyperextended knees and bilateral talipus with deformed lower limbs. $\mathbf{h}$ Postmortem image confirms the presence of the above findings

Due to the current pregnancy ultrasonographic findings, the diagnosis of WWS was suspected. The couple was advised to perform genetic testing. Amniocentesis was performed for whole exome sequencing (WES) analysis to confirm the underlying genetic cause. WES detected a homozygous pathogenic variant, c.924-2A>C, in the POMT2 gene; that was validated by Sanger sequencing (Fig. 2). The couple was informed with the poor prognosis of the condition that was confirmed by molecular testing; subsequently, they opted to terminate the pregnancy at 24 weeks' gestation and autopsy was declined.

The fetal weight was $645 \mathrm{~g}$; head circumference and CRL were $25 \mathrm{~cm}$ and $21.5 \mathrm{~cm}$, respectively. All these measurements were corresponding to 24-25 weeks of gestation. Physical examination showed a dysmorphic infant with macrocephaly, bilateral microphthalmia, bilateral cataracts, low-set ears, and micrognathia.

\section{Discussion}

The prenatal phenotype of WWS has not been fully delineated, and a small number of cases of prenatal diagnosis have been reported. Challenges in the prenatal detection of this syndrome have been recently highlighted in the literature [16, 23, 25-30]. The characteristic sonographic features, including hydrocephalus, ocular, cerebellar, and in some cases, meningocele, are considered non-specific, and therefore, a more definitive diagnosis could have been achieved only in the presence of family history [16, 23, 25-30]. This was demonstrated in a recent cohort of 65 cases including both fetuses and neonates, in which the diagnosis of index cases was achieved only after neuropathological evaluation [31, 32]. Another major difficulty is that pathognomonic signs of WWS including cobblestone lissencephaly and the double kink of the mesencephalic-pontine junction cannot be confirmed until the 3rd trimester, even with MRI or transvaginal ultrasonography [23, 30, 32]. A previous case report in 2005 detected lateral ventricles dilatation at 14 weeks of gestation, while hydrocephalus and the cobblestone lissencephaly were only evident at 30 weeks [25]. 


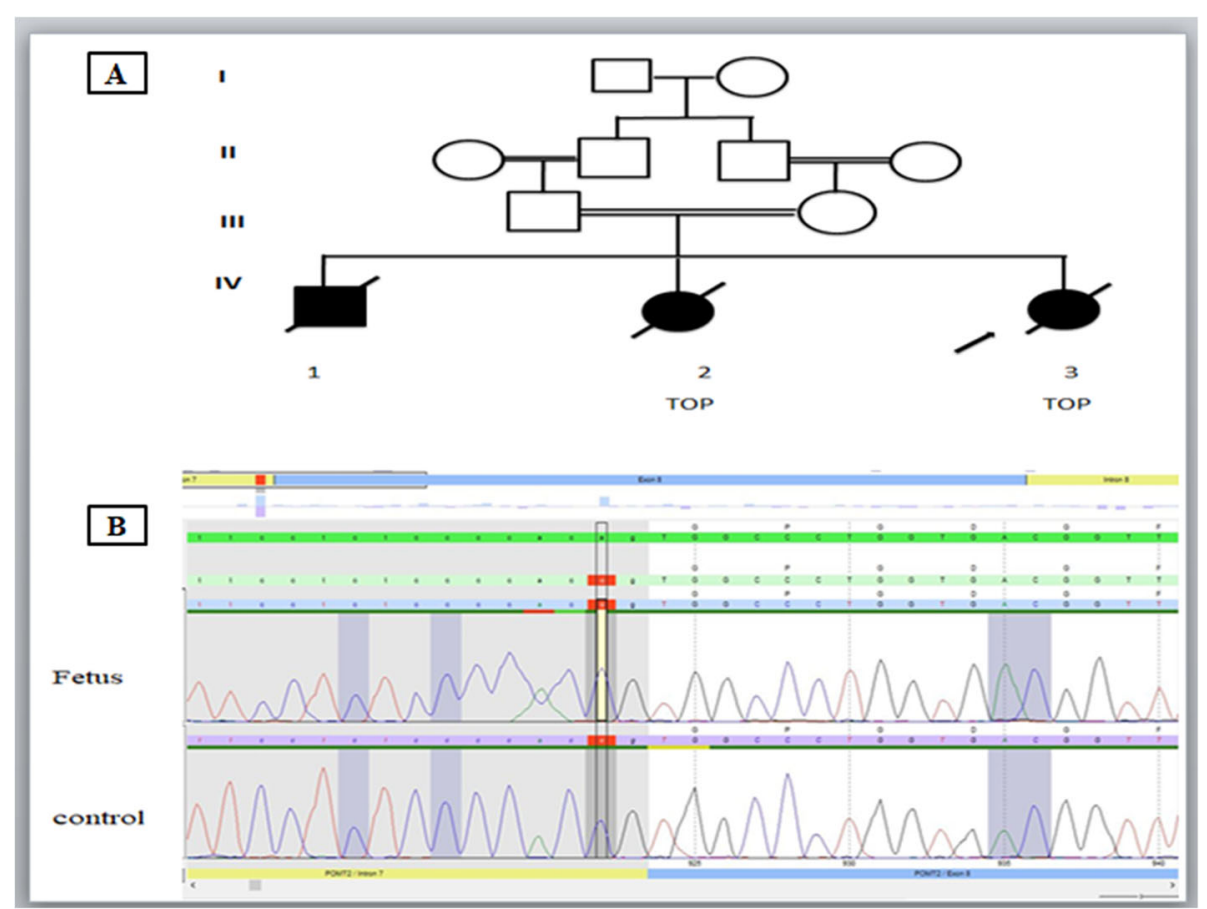

Fig. 2 POMT2 mutations and the pedigree in the fetus with Walker-Warburg syndrome. a Pedigree of the family showing the previous 2 affected siblings with arrow indicative of our index case. $\mathbf{b}$ Portion of the sequencing chromatogram showing the POMT2 pathogenic variant identified in our fetus; the POMT2 variant c.924-2A>C is predicted to disrupt the highly conserved acceptor splice site

The fetus we are reporting here presented with a diverse spectrum of manifestations with a suspected diagnosis of WWS. We managed to genetically confirm the diagnosis where WES identified a highly conserved splice site mutation in the POMT2 gene.

The triad of hydrocephalus, posterior fossa, and ocular abnormalities is considered a common feature for three closely related disorders: WWS, muscle-eye-brain (MEB) disease, and Fukuyama-type congenital muscular dystrophy (FCMD) [26, 32, 33]. As a result of the severe fetal phenotype in this report and the lethal course of the disease in this family, we present our fetus to have WWS rather than the less severe forms, which has a longer survival [32,33]. The characteristic cerebral and cerebellar malformations in WWS enabled its differentiation from other differential diagnoses including syndromes with lissencephaly as Miller-Dieker syndrome, Lowe Syndrome which is associated with bilateral cataract and cerebral anomalies and seen almost exclusively in male fetuses, X-linked lissencephaly with agenesis of the corpus callosum, and Norman-Roberts syndrome [26, 34, 35].

Congenital syndromic hydrocephalus is a common feature in various genetic disorders with different etiopathological mechanisms [36]. It has been shown that the defective glycosylation of $\alpha$-dystroglycan in WWS results in defective neuronal migration with subsequent severe cortical malformations and neuronal ectopia causing thickening in the leptomeninges. Secondary hydrocephalus results from the obliteration of the subarachnoid space caused by the irregular meningeal thickening $[8,29]$. In the present report, we demonstrated that anomalies of the posterior fossa appear before lateral ventricular dilation progressing to hydrocephalus which is considered a secondary process. The association between POMT2 mutations and cerebral anomalies not considered as constant features of WWS such as Dandy-Walker malformation, hypoplastic cerebellar vermis, and corpus callosum abnormalities has received little attention in prior prenatal studies [16, 23, 25-30]. Therefore, our findings expand the prenatal phenotypic spectrum of the disease.

The fetal orbits can be extensively evaluated during the 2nd trimester [37, 38]. A heterogeneous group of ocular abnormalities has been reported prenatally in WWS cases including orbital asymmetry, microphthalmia, persistent fetal vasculature, and cataract [39]. These ocular ultrasound findings have been detected at a relatively advanced stage of gestation preventing early intervention and counseling [23]. The ocular anomalies in the current case present at a relatively earlier gestational age of 20 weeks' gestation with a smaller orbit, cataract; additionally, we observed a hyperechogenic cord between the lens and the retina suggesting a hyperplastic primary vitreous. The prenatal diagnosis of persistent 
hyperplastic primary vitreous (PHPV), an abnormality resulting from incomplete embryonic primary vitreous regression, is extremely rare [40]. Similarly, as in our case, approximately $90 \%$ of cases of WWS, their ocular affections are asymmetrical [28].

Another striking finding in the fetus presented was the detection of a unilateral enlarged multicystic dysplastic kidney. This finding can be explained by the defective glycosylation occurring in the renal parenchyma, as the POMT2 gene is also expressed in the kidneys. The prenatal presentation of cystic kidneys has been described earlier in the literature in association with glycosylation defects [16, 41, 42]. Interestingly, although cystic renal involvement has been reported in the context of many other well-defined syndromes, it has been described in association with POMT2 mutation only in one case [16]. Other reports did not include cystic dysplastic kidneys in the renal phenotype of POMT2-associated disorders $[21,22]$. We here add the association of renal cystic disease to expand the spectrum of POMT2-associated WWS associated manifestations. Additionally, the uniqueness of the present case also lies in unilateral renal involvement.

Interestingly, in the current report, we detected both congenital heart disease and congenital contractures in the form of bilateral clenched hands and talipes. These features were not previously detected prenatally in fetuses with WWS and expand the phenotypic spectrum of this disorder.

The POMT2 variant c.924-2A>C identified in the present case is predicted to disrupt the highly conserved acceptor splice site. This variant has previously been described as disease-causing for Walker-Warburg syndrome by vanReeuwijk et al. [3], Bouchet et al. [43], Manzini et al. [44], and Abumansour et al. [29]. Although no clear-cut genotype-phenotype correlations were observed, however, it has been shown that homozygosity for the c.924-2A $>\mathrm{C}$ mutation resulting in severe disruption of the gene is associated with a consistently severe WWS phenotype [29].

\section{Conclusion}

In conclusion, this report expands the current prenatal phenotypic spectrum of POMT2 associated with WWS. Moreover, our case is unique as it delineates relatively early changes in the eyes, the brain, and kidneys, therefore shedding some light on the time sequence of the emergence of the malformations and adding previously described features of clenched hands and talipes equinovarus to this lethal fetal syndrome. Finally, we highlight the evolving power of prenatal imaging by highresolution ultrasound that improved the early characterization of fetal structural malformations. This in combination with systematic genomic studies might provide new insight into the distinguishing function of several genes acting during fetal life. Further, it permits obtaining a molecular diagnosis prenatally that can be used to confirm uncertain diagnoses and inform reproductive choices.

\begin{abstract}
Abbreviations
WWS: Walker-Warburg syndrome; $a$-DG: $a$-Dystroglycan; CK: Creatinine kinase; WES: Whole exome sequencing; MEB: Muscle-eye-brain disease; FCMD: Fukuyama-type congenital muscular dystrophy; PHPV: Persistent hyperplastic primary vitreous
\end{abstract}

\section{Acknowledgements}

We thank the family for their participation in this work

\section{Authors' contributions}

$\mathrm{SH}$ designed the study; collected, assembled, and interpreted the data; and wrote the manuscript. $\mathrm{HH}$ helped with the laboratory work and the genetic counseling. AE provided key information and helped revise the manuscript. MYI revised the manuscript and consulted the patient. All authors have read and approved the manuscript and ensure that this is the case.

\section{Funding}

The authors received no specific funding for this work.

\section{Availability of data and materials}

The data supporting the findings of this study are available with the corresponding author upon request.

\section{Ethics approval and consent to participate}

This research was reviewed and approved by the Medical Research Ethics Committee of the National Research Centre according to "World Medical Association Declaration of Helsinki," and written informed consent was obtained from the parents.

An informed consent to participate in the study was obtained from the parents of the patient, and a statement for this is included in the manuscript.

\section{Consent for publication}

Written informed consent was obtained from the parents of the patient for the publication of this case report and accompanying images.

\section{Competing interests}

The authors declare no conflict of interest.

\section{Author details}

${ }^{1}$ Prenatal Diagnosis \& Fetal Medicine Department, Human Genetics and Genome Research Division, National Research Centre, Tahrir street, Dokki, Cairo, Egypt. ${ }^{2}$ Centogene AG, Rostock, Germany. ${ }^{3}$ Fetal Medicine Unit, Cairo University, Cairo, Egypt. ${ }^{4}$ Clinical Genetics Department, Human Genetics and Genome Research Division, National Research Centre, Cairo, Egypt.

Received: 13 July 2020 Accepted: 27 August 2020

Published online: 23 November 2020

\section{References}

1. Godfrey C, Clement E, Mein R, Brockington M, Smith J, Talim B et al (2007) Refining genotype-phenotype correlations in muscular dystrophies with defective glycosylation of dystroglycan. Brain. 130:2725-2735

2. Dobyns WB, Pagon RA, Armstrong D, Curry CJ, Greenberg F, Holmes LB et al (1989) Diagnostic criteria for Walker-Warburg syndrome. Am J Med Genet 32(2):195-210

3. van Reeuwijk J, Janssen M, van den Elzen C, Beltran-Valero de Bernabe' D, Sabatelli P, Merlini L, et al (2005) POMT2 mutations cause a dystroglycanhypoglycosylation and Walker- Warburg syndrome. J Med Genet 42(12):907-912

4. Vajsar J, Schachter H (2006) Review Walker-Warburg syndrome. Orphanet J Rare Dis 1:29

5. Falsaperla R, Praticò AD, Ruggieri M, Parano E, Rizzo R, Corsello G et al (2016) Congenital muscular dystrophy: from muscle to brain. Ital J Pediatr 42(1):78 
6. Kang PB, Griggs RC (2015) Advances in muscular dystrophies. JAMA Neuro 72:741-742

7. Bouchet-Séraphin C, Vuillaumier-Barrot S, Seta N (2015) Dystroglycanopathies: about numerous genes involved in glycosylation of one single glycoprotein. J Neuromuscul Dis 2(1):27-38

8. Nickolls AR, Bönnemann CG (2018) The roles of dystroglycan in the nervous system: insights from animal models of muscular dystrophy. Dis Model Mech 11(12):dmm035931

9. Cormand B, Pihko H, Bayes M, Valanne L, Santavuori P, Gershoni-Baruch R et al (2001) Clinical and genetic distinction between Walker-Warburg syndrome and muscle-eye-brain disease. Neurology. 56:1059-1069

10. Trovato R, Astrea G, Bartalena L, Ghirri P, Balacci J, Baldacci J et al (2014) Elevated serum creatine kinase and small cerebellum prompt diagnosis of congenital muscular dystrophy due to FKRP mutations. J Child Neurol 29(3):394-398

11. Gerding H, Gullotta F, Kuchelmeister K, Busse H (1993) Ocular findings in Walker-Warburg syndrome. Childs Nerv Syst 9(7):418-420

12. Shen O, Zuckerman S, Cohen P, Rabinowitz R (2014) Prenatal sonographic diagnosis of retinal nonattachment. J Ultrasound Med 33:1095-1097

13. Mano N, Mitsutsuji T, Yoshikawa Y, Miyamoto M, Watanabe H, Shimizu K et al (2015) Optical coherence tomography in an infant with WalkerWarburg syndrome. Case Rep Ophthalmol 6:210-215

14. Vajsar J, Schachter H (2006) Walker-Warburg syndrome. Orphanet J Rare Dis 1:29

15. Pratap A, Agrawal A, Tiwari A, Lakshmi R, Rajbanshi S (2007) The WalkerWarburg syndrome with cleft lip and palate. Singap Med J 48(2):e66-e67

16. Nabhan MM, ElKhateeb N, Braun DA, Eun S, Saleem S, YungGee H et al (2017) Cystic kidneys in fetal Walker-Warburg syndrome with POMT2 mutation: Intrafamilial phenotypic variability in four siblings and review of literature. Am J Med Genet A 173(10):2697-2702

17. Gasser B, Lindner V, Dreyfus M, Feidt X, Leissner P, Stoll C (1998) Prenatal diagnosis of Walker-Warburg syndrome in three sibs. Am J Med Genet 76(2):107-110

18. Gee HY, Otto EA, Hurd TW, Ashraf S, Chaki M, Cluckey A et al (2014) Wholeexome resequencing distinguishes cystic kidney diseases from phenocopies in renal ciliopathies. Kidney Int 85(4):880-887

19. Trkova M, Krutilkova V, Smetanova D, Becvarova V, Hlavova E, Jencikova $\mathrm{N}$ et al (2015) ISPD gene homozygous deletion identified by SNP array confirms prenatal manifestation of Walker-Warburg syndrome. Eur J Med Genet 58(8):372-375

20. Muntoni F, Brockington M, Godfrey C, Ackroyd M, Robb S, Manzur A et al (2007) Muscular dystrophies due to defective glycosylation of dystroglycan. Acta Myol 26(3):129-135

21. Yanagisawa A, Bouchet C, Quijano-Roy S, Vuillaumier-Barrot S, Clarke N, Odent S et al (2009) POMT2 intragenic deletions and splicing abnormalities causing congenital muscular dystrophy with mental retardation. Europ J Med Genet 52:201206

22. Mercuri E, Messina S, Bruno C, Mora M, Pegoraro E, D'Amico A et al (2019) Congenital muscular dystrophies with defective glycosylation of dystroglycan: a population study. Neurology. 72:1802-1809

23. Achiron R, Katorza E, Reznik-Wolf H, Pras E, Kidron D, Berkenstadtt M (2016) Very early in-utero diagnosis of Walker-Warburg phenotype: the cutting edge of technology. Ultrasound Int Open 2(2):E54-E57

24. Cariati F, D'Argenio V, Tomaiuolo R (2019) The evolving role of genetic tests in reproductive medicine. J Transl Med 17:267

25. Blin G, Rabbé A, Ansquer Y, Meghdiche S, Floch-Tudal C, Mandelbrot L (2005) First-trimester ultrasound diagnosis in a recurrent case of WalkerWarburg syndrome. Ultrasound Obstet Gynecol 26(3):297-299

26. Chang W, Winder TL, LeDuc CA, Simpson LL, Millar WS, Dungan J et a (2009) Founder Fukutin mutation causes Walker-Warburg syndrome in four Ashkenazi Jewish families. Prenat Diagn 29:560-569

27. Yazicioglu HF, Ocak Z (2010) Walker Warburg syndrome with persistent hypoplastic primary vitreous detected by prenatal ultrasonography. Ultrasound Obstet Gynecol 35:246-249

28. Brasseur-Daudruy M, Vivier PH, Ickowicz V, Eurin D, Verspyck E (2012) Walker-Warburg syndrome diagnosed by findings of typical ocular abnormalities on prenatal ultrasound. Pediatr Radiol 42:488-490

29. Abumansour IS, Al Sulmi E, Chodirker BN, Hunt JC (2015) Prenatal diagnosis of Walker-Warburg syndrome using single nucleotide polymorphism array: a clinical experience from three related Palestinian families with congenital hydrocephalus. AJP Rep 5(2):e116-e120

30. Lacalm A, Nadaud B, Massoud M, Putoux A, Gaucherand P, Guibaud L et al (2016) Prenatal diagnosis of cobblestone lissencephaly associated with Walker-Warburg syndrome based on a specific sonographic pattern. Ultrasound Obstet Gynecol 47(1):117-122
31. Devisme L, Bouchet C, Gonzalès M, Alanio E, Bazin A, Bessières B et al (2012) Cobblestone lissencephaly: neuropathological subtypes and correlations with genes of dystroglycanopathies. Brain 135:469-468

32. Muntoni F, Brockington M, Torelli S, Brown SC (2004) Defective glycosylation in congenital muscular dystrophies. Curr Opin Neurol 17(2): 205-209

33. Tan AP, Chong WK, Mankad K (2018) Comprehensive genotype-phenotype correlation in lissencephaly. Quant Imaging Med Surg 8(7):673-693

34. Loi M (2006) Lowe syndrome. Orphanet J Rare Dis 1:16

35. Natacci F, Bedeschi MF, Righini A, Inverardi F, Rizzuti T, Boschetto C et al (2007) Norman-Roberts syndrome: characterization of the phenotype in early fetal life. Prenat Diagn 27(6):568-572

36. Etchegaray A, Juarez-Peñalva S, Petracchi F, Igarzabal L (2020) Prenatal genetic considerations in congenital ventriculomegaly and hydrocephalus. Childs Nerv Syst. https://doi.org/10.1007/s00381-020-04526-5

37. Hejtmancik J (2008) Congenital cataracts and their molecular genetics. Semin Cell Dev Biol 19:134-149

38. Drought A, Wimalasundera R, Holder S (2015) Ultrasound diagnosis of bilateral cataracts in a fetus with possible cerebro-ocular congential muscular dystrophy during the routine second trimester anomaly scan. Ultrasound. 23(3):181-185

39. Harding P, Moosajee M (2019) The molecular basis of human anophthalmia and microphthalmia. J Dev Biol 7:16

40. Esmer AC, Sivrikoz TS, Gulec EY, Sezar S, Kalelioglu I, Has R et al (2016) Prenatal diagnosis of persistent hyperplastic primary vitreous: report of 2 cases and review of the literature. J Ultrasound Med 35(10):2285-2291

41. Arora V, Bijarnia-Mahay S, Kulshreshtra S, Singh K, Puri RD, Chandar Verma I et al (2019) Prenatal presentation of a rare genetic disorder: a clinical, autopsy and molecular correlation. Autops Case Rep 9(4):e2019124

42. Soliman NA, Nabhan MM, Bazaraa HM, Badr AM, Shaheen M (2014) Clinical and ultrasonographical characterization of childhood cystic kidney diseases in Egypt. Ren Fail 36(5):694-700

43. Bouchet C, Gonzales M, Vuillaumier-Barrot S, Devisme L, Lebizec C, Alanio E et al (2007) Molecular heterogeneity in fetal forms of type II lissencephaly. Hum Mutat 28:1020-1027

44. Manzini MC, Gleason D, Chang BS, Sean Hill R, Barry BJ, Partlow JN et al (2008) Ethnically diverse causes of Walker-Warburg syndrome (WWS): FCMD mutations are a more common cause of WWS outside of the Middle East. Hum Mutat 29(11):E231-E241

\section{Publisher's Note}

Springer Nature remains neutral with regard to jurisdictional claims in published maps and institutional affiliations.

\section{Submit your manuscript to a SpringerOpen ${ }^{\circ}$ journal and benefit from:}

- Convenient online submission

- Rigorous peer review

- Open access: articles freely available online

- High visibility within the field

- Retaining the copyright to your article

Submit your next manuscript at $>$ springeropen.com 